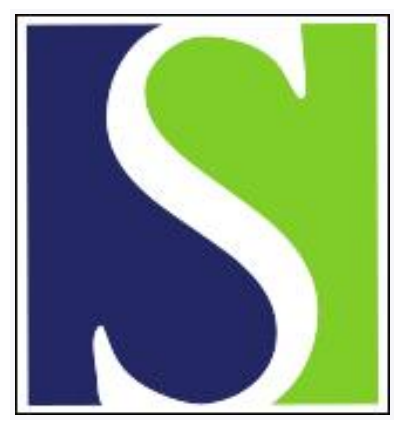

Scand J Work Environ Health 2005;31(6):465-673

https://doi.org/10.5271/sjweh.951

Issue date: 31 Dec 2005

Passive smoking exposure among adults and the dynamics of respiratory symptoms in a prospective multicenter cohort study

by Jayet P-Y, Schindler C, Schwartz J, Künzli N, Zellweger J-P, Ackermann-Liebrich $U$, Leuenberger $P$, SAPALDIA team

Affiliation: Service of Pulmonology, University Hospital CHUV, CH-1011 Lausanne, Switzerland. philippe.leuenberger@chuv.hospvd.ch

Key terms: epidemiology; exposure; longitudinal study; passive smoking; prospective multicenter cohort study; respiratory symptom; respiratory system; second-hand passive smoke

This article in PubMed: www.ncbi.nlm.nih.gov/pubmed/16425588 


\title{
Passive smoking exposure among adults and the dynamics of respiratory symptoms in a prospective multicenter cohort study
}

\author{
by Pierre-Yves Jayet, MD, ${ }^{1}$ Christian Schindler, PhD, ${ }^{2}$ Joel Schwartz, PhD, ${ }^{3}$ Nino Künzli, MD ${ }^{2,4}$ Jean- \\ Pierre Zellweger, MD, ${ }^{1}$ Ursula Ackermann-Liebrich, MD, ${ }^{2}$ Philippe Leuenberger, MD, ${ }^{1}$ SAPALDIA team ${ }^{5}$
}

\begin{abstract}
Jayet P-Y, Schindler C, Schwartz J, Künzli N, Zellweger J-P, Ackermann-Liebrich U, Leuenberger P, SAPALDIA team. Passive smoking exposure among adults and the dynamics of respiratory symptoms in a prospective multicenter cohort study. Scand J Work Environ Health 2005;31(6):465-473.
\end{abstract}

\begin{abstract}
Objectives The aim of this study was to measure the effects of past exposure to environmental tobacco smoke on the day-to-day dynamics of four respiratory-symptom classes in a diary study including adult never-smokers. Methods As part of SAPALDIA (Swiss study on air pollution and lung diseases in adults), a prospective multicenter cohort study, 1421 life-time adult nonsmokers were followed for 2 years with the use of daily questionnaires filled out during one to six periods of 4 weeks spread over 2 years (1992-1993). The hazard ratios (HR) of getting or losing respiratory symptoms from one day to another were determined in association with past exposure to environmental tobacco smoke.

Results In a sample of adult never-smokers, an association between self-reported past exposure to environmental tobacco smoke and deteriorated average symptom dynamics was found for all of the outcomes considered, showing HR values from 1.09 to 1.21 for developing symptoms and HR values from 0.91 to 0.83 for getting rid of them. Exposure to environmental tobacco smoke, including the workplace, was negatively associated with the length of intervals without symptoms of bronchitis (HR 1.33) and asthma (HR 1.27), while exposure to environmental tobacco smoke confined to places outside work was positively associated with the length of episodes of any respiratory symptom and lower-respiratory-tract symptoms (HR 0.78-0.77).

Conclusions The results suggest that exposure to environmental tobacco smoke has adverse effects on the dynamics of respiratory symptoms, and the size (magnitude) and type of effects appear to depend on the place of exposure.
\end{abstract}

Key terms epidemiology; longitudinal study; respiratory system; second-hand passive smoke.

Exposure to environmental tobacco smoke is now considered an important threat to the health of people who have never smoked, and it is a major contributor to indoor air pollution (1). While numerous studies and reports have shown adverse effects from exposure to environmental tobacco smoke, mainly on respiratory and cardiovascular health, most have been of cross-sectional design (2). Most of the few longitudinal studies have been performed with children, and the results of longitudinal studies on adults have been controversial (3-7). At a time when the tobacco industry contests the health effects of environmental tobacco smoke (8), longitudinal studies of adequate size are required to evaluate the influence of such exposure on the evolution of health status.

The association between chronic respiratory symptoms among adults and passive tobacco smoking has

1 Service of Pulmonology, University Hospital Lausanne, Switzerland.

2 Institute of Social and Preventive Medicine, University of Basle, Switzerland.

3 Department of Environmental Health, Harvard School of Public Health, Boston, Massachusetts, USA.

4 Division of Environmental Health, University of Southern California USC; Los Angeles, California, USA.

5 SAPALDIA team: P Leuenberger (p) (study director), U Ackermann-Liebrich (e) (program director), P Alean (am), K Blaser (a), G Bolognini (p), J-P Bongard (p), O Brändli (p), P Braun (p), C Bron (1), M Brutsche (l), C Defila (m), G Domenighetti (p), S Elsasser (1), L Grize (s), P Guldimann (1), P Hufschmid (1), W Karrer (p), H Keller-Wossidlo (o), R Keller (p), N Künzli (e), JC Lüthi (l), BW Martin (e), T Medici (p), C Monn (am), AG Peeters (pa), AP Perruchoud (p), A Radaelli (l), C Schindler (s), J Schwartz (s), G Solari (p), MH Schöni (p), JM Tschopp (p), B Villiger (p), B Wüthrich (a), J-P Zellweger (p), E Zemp (e). (a = allergology, am = air pollution monitoring, e = epidemiology, l= local assistant, $\mathrm{m}=$ meteorology, $\mathrm{o}=$ occupational medicine, $\mathrm{p}=$ pulmonology, $\mathrm{pa}=$ palynology, $\mathrm{s}=$ statistics)

Correspondence to: Dr Philippe Leuenberger, Service of Pulmonology, University Hospital CHUV, CH-1011 Lausanne, Switzerland. [E-mail: philippe.leuenberger@chuv.hospvd.ch] 
only been systematically investigated in the last 10 years. The report of the United States Environmental Protection Agency (EPA) entitled "Respiratory Health Effects of Passive Smoking: Lung Cancer and Other Disorders" published in 1992 (9) came to the conclusion that environmental tobacco smoke has subtle but significant effects on the respiratory health of nonsmokers, including increased coughing, phlegm production, chest discomfort, and even impairment of lung function. Since then, many recent epidemiologic studies have linked passive smoking with an increased risk of various respiratory symptoms such as dyspnea $(6,10,11)$, wheezing $(3,5,6,11)$, cough $(5,6,10,11)$, and phlegm $(5,6,10,11)$. A recent publication (12) investigating bartenders' respiratory health after the establishment of smoke-free bars in California interestingly showed a rapid improvement of all respiratory symptoms after the decrease in exposure to environmental tobacco smoke.

In the cross-sectional part of SAPALDIA (Swiss study on air pollution and lung diseases in adults) (1991), two different aspects of environmental exposure, namely, long-term air pollution (13) and environmental tobacco smoke (11), were associated with an elevated risk of developing respiratory symptoms. There was a dose-response relation between environmental tobacco smoke and several respiratory symptoms assessed by questionnaire. The additional objective of our present study was to determine the effects of environmental tobacco smoke on the dynamics of respiratory symptoms (ie, on the duration of symptom-free intervals and symptom episodes) using data from the SAPALDIA diary study (1992-1993).

\section{Study population and methods}

\section{Recruitment of the study population}

SAPALDIA is a multicenter study designed to investigate the relation between exposure to air pollution and respiratory symptoms and diseases. The study was conducted in eight areas (Aarau, Basel, Davos, Geneva, Lugano, Montana, Payerne, and Wald) representing a wide range of environmental characteristics in Switzerland.

The cross-sectional part was conducted in 1991 to assess the prevalence of respiratory and allergic diseases, and it involved 9651 adults, aged 18-60 years. A detailed description of the cross-sectional study has been given elsewhere (14), and many results have already been published $(11,13,15-18)$.

The SAPALDIA diary study took place from 1992 to 1993 . It collected additional data on symptom dynamics and provided the basis for our present analysis. For this study, all people having reported lower respiratory symptoms or current asthma or having shown bronchial obstruction or bronchial hyperreactivity in the preceding cross-sectional examination were invited to participate, with the purpose of enhancing the statistical power of the study to assess the effects of risk factors on respiratory symptoms among relevant subgroups. In addition, from each study area, 150 randomly selected nonsmokers not belonging to any of the aforementioned categories were invited to serve as local control groups. These selection criteria are described in detail in the following section.

\section{Study population}

In our study, the analyses were restricted to life-time nonsmokers, representing 1421 persons or $43.3 \%$ $(\mathrm{N}=3279)$ of the sample of the longitudinal study. Never-smokers were defined as life-time nonsmokers who, by the time of the cross-sectional examination, had smoked less than 20 packs of cigarettes or less than 360 grams of tobacco in their entire life and who did not smoke during the diary study. On the basis of the follow-up inclusion criteria, this sample was divided into the following five subgroups: the bronchitis cohort, the asthma cohort, the silent obstruction cohort, the asymptomatic hyperreactivity cohort, and the healthy cohort.

The cohort of bronchitic never-smokers $(\mathrm{N}=349)$ comprised all participants having reported at least one of the following characteristics in the cross-sectional survey: regular nocturnal or diurnal cough or regular nocturnal or diurnal phlegm or both.

After the people with the bronchitis symptoms were excluded, the cohort of asthmatic never-smokers $(\mathrm{N}=358)$ comprised all of the participants who had reported at least one of the following characteristics in the cross-sectional survey: wheezing or whistling in the chest during the last 12 months, nocturnal tightness at any time in the last 12 months, nocturnal or diurnal attacks of dyspnea during the day in the last 12 months, an asthma attack in the last 12 months, and current use of asthma medication.

The participants $(\mathrm{N}=18)$ without any of the aforementioned symptoms, but with airway obstruction [ie, with a forced expiratory volume in 1 second $\left(\mathrm{FEV}_{1}\right)$ of $<70 \%$ of the predicted value or an $\mathrm{FEV}_{1} / \mathrm{FVC}$ ratio of $<80 \%$ of the predicted value] formed the silent obstruction group. Because of the small size of the cohort with silent obstruction, no separate analyses were done for this subgroup.

The participants $(\mathrm{N}=181)$ without any of the aforementioned characteristics, but having shown a decline in their $\mathrm{FEV}_{1}$ of at least $20 \%$ from baseline during a methacholine broncho-challenge with a maximal cumulative dose of 2 milligrams (obstructive participants having been excluded from this test) comprised the asymptomatic hyperreactivity group. 
The healthy cohort $(\mathrm{N}=515)$ was formed of neversmokers not belonging to any of the aforementioned cohorts.

The proportions of these cohorts differed between the cross-sectional and the diary study. The cohorts of bronchitic and asthmatic people, respectively, as well as the cohort of asymptomatic hyperreactives were oversampled in the diary study population. Within this population, the proportion of symptomatic (ie, bronchitic or asthmatic) people was smaller among the never-smokers than among the current or former smokers, whereas the opposite was true for the proportions of healthy and asymptomatic hyperreactive participants. Detailed characteristics of the study population are provided in tables 1 and 2 .

\section{Study schedule and data collection}

In order to keep the number of participants as stable as possible, the persons enrolled in the diary study were divided into 16 groups of equal size in each area, using stratified randomization. The groups were enrolled at intervals of 1 week, and each participant was invited to keep a diary for six periods of 4 weeks separated by intervals of 3 months. Altogether 3279 persons, corresponding to a participation rate of $61 \%$, completed their diary for up to six periods of 4 weeks within 2 years. During the diary periods the participants recorded symptoms on a daily basis. Symptoms of phlegm, sore throat, hoarseness, running or stuffy nose, itchy or irritated eyes, reduced activity, and fever had to be reported in the evening for the past 24-hour period. But wheezing, dyspnea, chest tightness, and cough were reported in the morning (for the preceding night) and in the evening (for the daytime period).

\section{Assessment of exposure to environmental tobacco smoke}

Exposure to environmental tobacco smoke was assessed in the cross-sectional interview conducted in

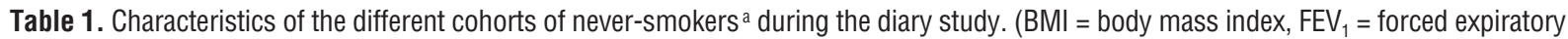
volume in 1 second, $\mathrm{FVC}$ = forced vital capacity, $\mathrm{PD}_{20}$ = provocating dose of methacholine producing a $20 \%$ decrease in the $\mathrm{FEV}_{1}$ )

\begin{tabular}{|c|c|c|c|c|c|c|c|c|c|c|c|c|c|c|c|c|}
\hline \multirow[t]{3}{*}{ Cohort } & \multicolumn{16}{|c|}{ Characteristics } \\
\hline & \multirow[t]{2}{*}{$\begin{array}{l}\text { Male } \\
(\%)\end{array}$} & \multicolumn{2}{|c|}{$\begin{array}{c}\text { Age } \\
\text { (years) }\end{array}$} & \multicolumn{2}{|c|}{$\begin{array}{c}\mathrm{BMI} \\
\left(\mathrm{kg} / \mathrm{m}^{2}\right)\end{array}$} & \multicolumn{2}{|c|}{$\begin{array}{l}\text { Documented } \\
\text { diary days }\end{array}$} & \multirow{2}{*}{$\begin{array}{l}\text { Low } \\
\text { edu- } \\
\text { cation } \\
(\%)\end{array}$} & \multirow{2}{*}{$\begin{array}{c}\text { Foreign } \\
\text { nation- } \\
\text { ality } \\
(\%)\end{array}$} & \multirow{2}{*}{$\begin{array}{c}\text { Daily } \\
\text { use of } \\
\text { respir- } \\
\text { atory } \\
\text { drugs } \\
(\%)\end{array}$} & \multicolumn{2}{|c|}{$\begin{array}{l}\mathrm{FEV}_{1}(\% \\
\text { of predicted) }\end{array}$} & \multicolumn{2}{|c|}{$\begin{array}{l}\mathrm{FEV}_{1} / \mathrm{FVC}(\% \\
\text { of predicted) }\end{array}$} & \multicolumn{2}{|c|}{$\mathrm{PD}_{20}<2 \mathrm{mg}$} \\
\hline & & Mean & $\mathrm{SD}$ & Mean & SD & $\begin{array}{c}\text { Mean } \\
\text { du- } \\
\text { ration }\end{array}$ & $\begin{array}{l}\text { Inter- } \\
\text { quartile } \\
\text { range }\end{array}$ & & & & Mean & SD & Mean & $\mathrm{SD}$ & $\begin{array}{l}\text { Men } \\
(\%)\end{array}$ & $\begin{array}{l}\text { Wo- } \\
\text { men } \\
(\%)\end{array}$ \\
\hline Healthy $(\mathrm{N}=515)$ & 46.6 & 39.9 & 11.6 & 23.3 & 3.5 & 156 & $98-168$ & 11.3 & 10.9 & 0 & 102 & 11.8 & 101.0 & 7.0 & 0 & 0 \\
\hline $\begin{array}{l}\text { Asymptomatic } \\
\text { hyperreactivity ( } \mathrm{N}=181)\end{array}$ & 28.7 & 39.4 & 12.6 & 23.8 & 4.0 & 160 & $84-168$ & 12.7 & 7.7 & 0 & 96.4 & 11.6 & 98.0 & 8.2 & 100 & 100 \\
\hline Bronchitis symptoms ( $N=349)$ & 42.7 & 43.2 & 11.7 & 23.9 & 3.7 & 146 & $84-168$ & 14.7 & 14.9 & 6.5 & 98.5 & 15.0 & 99.2 & 9.7 & $13.8^{\mathrm{b}}$ & $27.9^{b}$ \\
\hline Asthma symptoms ( $\mathrm{N}=358)$ & 31.8 & 44.2 & 11.8 & 24.3 & 4.1 & 143 & 63-168 & 18.2 & 14.2 & 3.3 & 98.7 & 15.3 & 98.6 & 9.6 & $26.8^{\mathrm{b}}$ & $31.0^{\mathrm{b}}$ \\
\hline Total $(\mathrm{N}=1421)^{\mathrm{c}}$ & 39.6 & 41.8 & 12.0 & 23.8 & 3.8 & 152 & $84-168$ & 14.2 & 12.5 & 2.4 & 97.4 & 14.0 & 97.9 & 11.0 & $19.0^{\mathrm{b}}$ & $32.4^{\mathrm{b}}$ \\
\hline
\end{tabular}

Table 2. Symptom-free intervals and symptom episodes reported during the diary study.

\begin{tabular}{|c|c|c|c|c|c|c|c|c|}
\hline \multirow[t]{4}{*}{ Cohort } & \multicolumn{8}{|c|}{ Characteristics } \\
\hline & \multicolumn{4}{|c|}{ Average symptom-free intervals (days) } & \multicolumn{4}{|c|}{ Average symptom episodes (days) } \\
\hline & \multicolumn{2}{|c|}{$\begin{array}{l}\text { Bronchitis symptoms } \\
\qquad(\mathrm{N}=1394)\end{array}$} & \multicolumn{2}{|c|}{$\begin{array}{l}\text { Asthma symptoms } \\
\qquad(\mathrm{N}=1413)\end{array}$} & \multicolumn{2}{|c|}{$\begin{array}{l}\text { Bronchitis symptoms } \\
\qquad(\mathrm{N}=976)\end{array}$} & \multicolumn{2}{|c|}{$\begin{array}{l}\text { Asthma symptoms } \\
\qquad(\mathrm{N}=631)\end{array}$} \\
\hline & $\begin{array}{l}\text { Mean } \\
\text { duration }\end{array}$ & $\begin{array}{l}\text { Interquartile } \\
\text { range }\end{array}$ & $\begin{array}{l}\text { Mean } \\
\text { duration }\end{array}$ & $\begin{array}{l}\text { Interquartile } \\
\text { range }\end{array}$ & $\begin{array}{l}\text { Mean } \\
\text { duration }\end{array}$ & $\begin{array}{l}\text { Interquartile } \\
\text { range }\end{array}$ & $\begin{array}{l}\text { Mean } \\
\text { duration }\end{array}$ & $\begin{array}{l}\text { Interquartile } \\
\text { range }\end{array}$ \\
\hline Healthy $(\mathrm{N}=515)$ & 82.3 & $37.0-153.0$ & 139.0 & $70.0-160.0$ & 4.0 & $2.0-6.6$ & 1.7 & $1.0-4.0$ \\
\hline Asymptomatic hyperreactivity $(\mathrm{N}=181)$ & 64.0 & $28.0-143.0$ & 106.5 & $35.4-160.0$ & 3.8 & $2.0-7.7$ & 2.0 & $1.0-3.3$ \\
\hline Bronchitis symptoms ( $\mathrm{N}=349)$ & 26.0 & $9.6-67.3$ & 71.0 & $27.0-154.0$ & 4.3 & $2.4-10.0$ & 2.0 & $1.1-3.8$ \\
\hline Asthma symptoms ( $\mathrm{N}=358)$ & 44.0 & $21.0-118.0$ & 49.0 & $19.8-134.0$ & 3.0 & $2.0-6.7$ & 2.0 & $1.2-3.7$ \\
\hline Total $(\mathrm{N}=1421)^{\text {a }}$ & 51.3 & $23.5-133.0$ & 99.0 & $32.0-157.0$ & 4.0 & $2.0-7.2$ & 2.0 & $1.0-3.7$ \\
\hline
\end{tabular}

a Including 18 participants with silent obstruction. 
1991. People who answered affirmatively to exposure to environmental tobacco smoke during the past 12 months were asked whether they were currently exposed to such smoke at their workplace; environmental tobacco smoke exposure anywhere was then divided into the following two categories: exposure confined to places outside work and exposure at the workplace and possibly elsewhere.

The exposed persons were asked three additional questions in an attempt to quantify the exposure: "How many hours per day are you exposed to the tobacco smoke of other people?", "To how many smokers have you been regularly exposed to closely?", and "During how many years have you been exposed?"

\section{Health outcomes}

One of the main interests of the diary study was the assessment of the dynamic patterns of various respiratory symptoms and conditions. We have defined and analyzed the following four symptom classes separately: (i) any respiratory symptom (presence of any of the respiratory symptoms asked about in the diary), (ii) lower respiratory symptoms (wheezing, dyspnea, chest tightness, cough, or phlegm), (iii) bronchitis symptoms (cough or phlegm), and (iv) asthma-like symptoms (wheezing, dyspnea, or chest tightness).

\section{Statistical analysis}

Since the participants of our diary study did not report over a continuous time interval but instead during separate periods of 4 weeks, personal estimates of the average duration of symptom-free intervals and symptom episodes were obtained using transition probabilities. If a participant never (or always) reported symptoms of a specific type, then the number of documented pairs of neighboring days was used as a censored estimate of the average duration of his or her symptom-free intervals (or symptom episodes). Otherwise, the inverse values of the conditional probability of changing symptom state were used as uncensored estimates of the average durations of symptom-free intervals and symptom episodes (17). To study the effects of exposure to environmental tobacco smoke on these durations, Cox proportional hazard regression was used. In addition to the variable(s) of exposure to environmental tobacco smoke, our models included dummy variables for female gender, parental history of asthma, parental history of allergies, low education, foreign citizenship, occupational exposure to airborne irritants, and the quantitative variables age (with a linear and a quadratic term), body mass index, and percentage of diary days occurring in the winter season. Moreover, the estimation of the baseline hazard function was stratified by study area. In addition, the analyses were stratified by cohort, to take account of existing differences in the baseline hazard functions and to detect the potential heterogeneity of the effects of environmental tobacco smoke across the cohorts. In the examination of the potential dose-response relation, the different exposure parameters (ie, number of smokers to which the participant was exposed, daily number of hours of exposure, past exposure in years) were categorized into three levels ("unexposed participants" and two groups of exposed participants of about equal size). Most of the statistical analyses were done using the SAS, version 6.09 software (SAS Institute, Cary, NC, USA).

\section{Results}

\section{Exposure to environmental tobacco smoke among never-smokers}

The frequencies of the different categories of self-reported past exposure to environmental tobacco smoke are given in table 3 . Altogether $27 \%$ of our study population had reported exposure to environmental tobacco

Table 3. Exposure to environmental tobacco smoke during the 12 months preceding the cross-sectional examination among the neversmokers taking part in the diary study.

\begin{tabular}{|c|c|c|c|c|c|c|c|c|c|c|c|c|c|c|c|}
\hline \multirow{3}{*}{$\begin{array}{l}\text { Exposure to } \\
\text { environmental } \\
\text { tomacco smoke a }\end{array}$} & \multicolumn{10}{|c|}{ Cohort } & \multirow{2}{*}{\multicolumn{2}{|c|}{$\begin{array}{l}\text { Hours of } \\
\text { exposure } \\
\text { per day }\end{array}$}} & \multirow{2}{*}{\multicolumn{2}{|c|}{$\begin{array}{c}\text { Smokers } \\
\text { exposed to } \\
\text { environmental } \\
\text { tobacco smoke }\end{array}$}} & \multirow{2}{*}{$\begin{array}{l}\text { Years of } \\
\text { exposure }\end{array}$} \\
\hline & \multicolumn{2}{|c|}{ Healthy } & \multicolumn{2}{|c|}{$\begin{array}{l}\text { Asymptomatic } \\
\text { hyperreactivity }\end{array}$} & \multicolumn{2}{|c|}{ Bronchitis } & \multicolumn{2}{|c|}{ Asthma } & \multicolumn{2}{|c|}{ Total $^{b}$} & & & & & \\
\hline & $\mathrm{N}$ & $\%$ & $\mathrm{~N}$ & $\%$ & $\mathrm{~N}$ & $\%$ & $\mathrm{~N}$ & $\%$ & $\mathrm{~N}$ & $\%$ & Mean & SD & Mean & SD & Mean SD \\
\hline Nowhere & 392 & 76.1 & 134 & 74.0 & 237 & 67.9 & 261 & 72.9 & 1037 & 73.0 & & & & & \\
\hline Anywhere & 123 & 23.9 & 47 & 26.0 & 112 & 32.1 & 97 & 27.1 & 384 & 27.0 & 3.8 & 3.1 & 5.1 & 8.4 & 23.114 .5 \\
\hline Not at workplace & 56 & 10.9 & 24 & 13.3 & 35 & 10.0 & 40 & 11.2 & 158 & 11.1 & $2.5^{c}$ & 2.0 & $2.6^{c}$ & 3.4 & 24.314 .9 \\
\hline $\begin{array}{l}\text { At workplace and possibly } \\
\text { elsewhere }\end{array}$ & 67 & 13.0 & 22 & 12.2 & 75 & 21.5 & 55 & 15.4 & 221 & 15.6 & $4.5^{c}$ & 3.4 & $7.1^{c}$ & 10.4 & 22.014 .1 \\
\hline
\end{tabular}

a Five participants with exposure to environmental tobacco smoke had no information on whether they were exposed at work.

b Including 18 participants with silent obstruction.

c $P<0.001$. 
smoke in the cross-sectional interview in 1991, and more than half of these people were exposed at their workplace, with or without additional exposure elsewhere. The participants with bronchitic or asthmatic symptoms reported exposure to environmental tobacco smoke more often at the workplace than the participants in the healthy and hyperreactive cohorts $(21.5 \%$ and $15.3 \%$, respectively, versus $13.0 \%$ and $12.2 \%$, respectively). On the average, the participants who had reported current exposure at work also reported more hours of exposure $(\mathrm{P}<0.001)$ and higher numbers of persons to which they were exposed $(\mathrm{P}<0.001)$ than those who were only exposed outside the workplace. The number of years of exposure was similar for both of the exposure categories.

\section{Exposure to environmental tobacco smoke and the hazard ratios for becoming symptomatic or symptom- free}

Table 4 shows the adjusted hazard ratios of developing symptoms among never-smokers in general according to exposure to environmental tobacco smoke. For all of the symptom classes examined, a tendency towards a shortening of symptom-free intervals [ie, an increased risk of (re)developing symptoms after having been symptom-free] was found among the participants exposed to environmental tobacco smoke. For instance, with a hazard ratio of 1.21 , the risk of (re)developing bronchitis symptoms was $21 \%$ higher among the participants exposed to environmental tobacco smoke than among the unexposed participants. For all four symptom classes, the risk of (re)developing symptoms was increased when exposure to environmental tobacco smoke occurred at work and possibly elsewhere, whereas the corresponding risks were not elevated when exposure occurred outside work only.

Table 4 also shows that, conversely, the participants only exposed to environmental tobacco smoke outside work had a lower chance of recovering from any respiratory symptom or lower-respiratory-tract symptoms than the unexposed participants, the implication being that episodes of such symptoms tended to last longer in this exposure category. For instance, with a hazard ratio of 0.77 , the chance of getting rid of lower respiratory symptoms was $23 \%$ lower within this exposure category than for unexposed persons.

The hazard ratios for changing symptom status in association with different exposure categories for environmental tobacco smoke varied across the four cohorts (table 5). For the cohorts of healthy persons or persons with asthma or bronchitis symptoms, our findings were consistent with adverse effects of environmental tobacco smoke on any respiratory symptom and symptoms of the lower respiratory tract, respectively, and on bronchitis symptoms, both by shortening intervals without such symptoms (reflected by hazard ratios of $>1$ for getting symptoms) and by increasing the length of episodes of such symptoms (reflected by hazard ratios of $<1$ for becoming symptom-free). Within the asthma cohort, the episodes of asthma symptoms tended to last longer among the participants exposed to environmental tobacco smoke, but the length of the intervals without such symptoms did not seem to be affected. The participants in the asymptomatic hyperreactivity cohort tended to have longer symptom-free intervals and shorter symptom episodes (ie, fewer symptoms) when exposed to environmental tobacco smoke. In this cohort, the average duration of episodes of any respiratory symptom, symptoms of the lower respiratory tract, and bronchitis

Table 4. Estimated hazard ratio a for never-smokers getting or losing respiratory symptoms in different categories of exposure to environmental tobacco smoke. (95\% $\mathrm{Cl}=95 \%$ confidence interval)

\begin{tabular}{|c|c|c|c|c|c|c|c|c|c|c|c|}
\hline \multirow[t]{4}{*}{ Type of symptoms } & \multicolumn{11}{|c|}{ Exposure to environmental tobacco smoke } \\
\hline & \multicolumn{6}{|c|}{ Becoming symptomatic ${ }^{b}$} & \multicolumn{5}{|c|}{ Becoming symptom-free ${ }^{b}$} \\
\hline & \multicolumn{2}{|c|}{ Anywhere } & \multicolumn{2}{|c|}{ Not at work } & \multicolumn{2}{|c|}{$\begin{array}{c}\text { At work and } \\
\text { possibly elsewhere }\end{array}$} & \multirow{2}{*}{$\begin{array}{c}\text { Anywhere } \\
\begin{array}{c}\text { Hazard } 95 \% \mathrm{Cl} \\
\text { ratio }\end{array}\end{array}$} & \multicolumn{2}{|c|}{ Not at work } & \multicolumn{2}{|c|}{$\begin{array}{c}\text { At work and } \\
\text { possibly elsewhere }\end{array}$} \\
\hline & $\begin{array}{c}\text { Hazard } \\
\text { ratio }\end{array}$ & $95 \% \mathrm{Cl}$ & $\begin{array}{l}\text { Hazard } \\
\text { ratio }\end{array}$ & $95 \% \mathrm{Cl}$ & $\begin{array}{l}\text { Hazard } \\
\text { ratio }\end{array}$ & $95 \% \mathrm{Cl}$ & & $\begin{array}{c}\text { Hazard } \\
\text { ratio }\end{array}$ & $95 \% \mathrm{Cl}$ & $\begin{array}{c}\text { Hazard } \\
\text { ratio }\end{array}$ & $95 \% \mathrm{Cl}$ \\
\hline Any respiratory symptom ${ }^{c}$ & 1.14 & $0.99-1.30$ & 1.08 & $0.89-1.31$ & 1.17 & $0.99-1.39$ & $0.910 .79-1.04$ & 0.78 & $0.64-0.95$ & 1.00 & $0.84-1.18$ \\
\hline $\begin{array}{l}\text { Symptoms of the lower } \\
\text { respiratory tract }{ }^{c}\end{array}$ & 1.14 & $0.99-1.32$ & 0.98 & $0.80-1.21$ & 1.28 & $1.07-1.52$ & $0.83 \quad 0.72-0.96$ & 0.77 & $0.63-0.96$ & 0.87 & $0.73-1.04$ \\
\hline Bronchitis symptoms ${ }^{c}$ & 1.21 & $1.04-1.40$ & 1.05 & $0.85-1.30$ & 1.33 & $1.11-1.59$ & $0.84 \quad 0.72-0.98$ & 0.81 & $0.65-1.01$ & 0.86 & $0.71-1.03$ \\
\hline Asthma symptoms ${ }^{c}$ & 1.09 & $0.90-1.30$ & 0.86 & $0.66-1.14$ & 1.27 & $1.02-1.58$ & $0.85 \quad 0.70-1.03$ & 0.76 & $0.56-1.01$ & 0.91 & $0.73-1.14$ \\
\hline
\end{tabular}


Table 5. Estimated hazard ratio a $(\mathrm{HR})$ for the different cohorts of never-smokers becoming symptomatic or symptom-free with respect to respiratory symptoms in the different categories of exposure to environmental tobacco smoke. $(95 \% \mathrm{Cl}=95 \%$ confidence interval)

\begin{tabular}{|c|c|c|c|c|c|c|c|c|c|c|c|}
\hline \multirow[t]{4}{*}{ Cohort } & \multicolumn{11}{|c|}{ Exposure to environmental tobacco smoke } \\
\hline & \multicolumn{6}{|c|}{ Becoming symptomatic ${ }^{b}$} & \multicolumn{5}{|c|}{ Becoming symptom-free ${ }^{b}$} \\
\hline & \multicolumn{2}{|c|}{ Anywhere } & \multicolumn{2}{|c|}{ Not at work } & \multicolumn{2}{|c|}{$\begin{array}{c}\text { At work and } \\
\text { possibly elsewhere }\end{array}$} & Anywhere & \multicolumn{2}{|c|}{ Not at work } & \multicolumn{2}{|c|}{$\begin{array}{l}\text { At work and } \\
\text { possibly elsewhere }\end{array}$} \\
\hline & $\begin{array}{l}\text { Hazard } \\
\text { ratio }\end{array}$ & $95 \% \mathrm{Cl}$ & $\begin{array}{l}\text { Hazard } \\
\text { ratio }\end{array}$ & $95 \% \mathrm{Cl}$ & $\begin{array}{l}\text { Hazard } \\
\text { ratio }\end{array}$ & $95 \% \mathrm{Cl}$ & $\begin{array}{l}\text { Hazard } 95 \% \mathrm{Cl} \\
\text { ratio }\end{array}$ & $\begin{array}{l}\text { Hazard } \\
\text { ratio }\end{array}$ & $95 \% \mathrm{Cl}$ & $\begin{array}{l}\text { Hazard } \\
\text { ratio }\end{array}$ & $95 \% \mathrm{Cl}$ \\
\hline \multicolumn{12}{|l|}{ Healthy $(\mathrm{N}=515)$} \\
\hline Any respiratory symp & 1.18 & $0.91-1.54$ & 1.16 & $0.81-1.66$ & 1.20 & $0.86-1.67$ & $0.95 \quad 0.72-1.24$ & 0.84 & $0.58-1.23$ & 1.04 & $0.74-1.46$ \\
\hline $\begin{array}{l}\text { Symptoms of the lower } \\
\text { respiratory tract }{ }^{c}\end{array}$ & 1.12 & $0.84-1.50$ & 1.08 & $0.73-1.58$ & 1.17 & $0.80-1.71$ & $0.87 \quad 0.64-1.17$ & 0.87 & $0.58-1.31$ & 0.86 & $0.59-1.26$ \\
\hline Bronchitis symptoms ${ }^{c}$ & 1.29 & $5-1.73$ & 1.27 & 0.85 & 1.30 & 0.89 & $0.96 \quad 0.71-1.29$ & 0.91 & 0.6 & 1.00 & 0.68 \\
\hline Asthma symptoms ${ }^{c}$ & 0.91 & $0.59-1.40$ & 0.59 & $0.30-1.15$ & 1.25 & $0.74-2.10$ & $\begin{array}{ll}0.67 & 0.39-1.13\end{array}$ & 0.79 & 1.90 & 0.63 & $0.35-1.13$ \\
\hline \multicolumn{12}{|l|}{ Hyperreactivity ( $\mathrm{N}=181$ ) } \\
\hline Any respiratory symptom ${ }^{c}$ & 1.07 & $0.71-1.60$ & 1.19 & $0.68-2.07$ & 0.99 & 1.72 & $1.801 .15-2.82$ & 1.22 & $0.67-$ & 2.94 & $1.63-5.32$ \\
\hline $\begin{array}{l}\text { Symptoms of the lower } \\
\text { respiratory tract }{ }^{c}\end{array}$ & 0.87 & $0.56-1.34$ & 0.74 & $0.39-1.39$ & 0.97 & $0.56-1.69$ & $1.991 .22-3.25$ & 1.69 & $0.85-3.34$ & 2.37 & $1.26-4.45$ \\
\hline Bronchitis symptoms ${ }^{c}$ & 0.93 & $0.58-1.46$ & 0.79 & $0.41-1.53$ & 1.00 & $0.55-1.80$ & $2.021 .20-3.39$ & 1.51 & $0.76-2.99$ & 2.81 & $1.43-5.53$ \\
\hline Asthma symptoms ${ }^{c}$ & 0.79 & $0.46-1.36$ & 0.80 & $0.39-1.64$ & 0.75 & $0.36-1.58$ & $0.850 .42-1.69$ & 0.73 & $0.30-1.79$ & 2.01 & $0.77-5.22$ \\
\hline \multicolumn{12}{|l|}{ Bronchitis (N=349) d } \\
\hline Any respiratory symptom & 1.17 & $0.90-1.52$ & 1.31 & $0.87-1.98$ & 1.12 & $0.82-1.52$ & $0.890 .68-1.17$ & 0.70 & $0.46-1.06$ & 1.00 & $0.73-1.37$ \\
\hline $\begin{array}{l}\text { Symptoms of the lower } \\
\text { respiratory tract }{ }^{c}\end{array}$ & 1.26 & $0.96-1.65$ & 1.44 & $0.94-2.22$ & 1.19 & $0.87-1.63$ & $0.790 .59-1.05$ & 0.65 & $0.42-1.01$ & 0.86 & $0.62-1.19$ \\
\hline Bronchitis symptoms ${ }^{c}$ & 1.33 & $1.01-1.75$ & 1.50 & $0.97-2.32$ & 1.26 & $0.92-1.73$ & 0.780 .5 & 0.61 & .96 & 0.88 & $0.63-1.22$ \\
\hline Asthma symptoms ${ }^{\S}$ & 1.11 & $0.80-1.55$ & 1.00 & $0.58-1.71$ & 1.16 & $0.79-1.70$ & $1.040 .72-1.50$ & 1.08 & $0.60-1.94$ & 1.01 & $0.67-1.54$ \\
\hline \multicolumn{12}{|l|}{ Asthma $(\mathrm{N}=359)^{\mathrm{d}}$} \\
\hline Any respiratory sy & 1.06 & $0.81-$ & 0.99 & 0.67 & 1.11 & $0.7 \mathrm{~s}$ & 0.780 .6 & 0.79 & 0.5 & 0.75 & $0.53-1.05$ \\
\hline $\begin{array}{l}\text { Symptoms of the lower } \\
\text { respiratory tract }{ }^{c}\end{array}$ & 1.09 & $0.82-1.44$ & 0.84 & $0.55-1.29$ & 1.34 & $0.95-1.89$ & $0.77 \quad 0.58-1.03$ & 0.74 & $0.47-1.18$ & 0.79 & $0.56-1.12$ \\
\hline Bronchitis symptoms ${ }^{c}$ & 1.09 & $0.81-1.48$ & 0.84 & 32 & 1.34 & & 0.770 .5 & 0.96 & & 0.69 & $0.48-1.01$ \\
\hline Asthma symptoms c & 0.93 & $0.67-1.30$ & 0.80 & $0.49-1.32$ & 1.09 & $0.73-1.62$ & $0.77 \quad 0.54-1.10$ & 0.61 & $0.34-1.08$ & 0.88 & $0.57-1.35$ \\
\hline
\end{tabular}

${ }^{a}$ Respective cohorts of never-smokers without exposure to environmental tobacco smoke being the reference category.

$\mathrm{b}$ If the hazard ratio for becoming symptomatic is $>1$, then the symptom-free intervals are shorter; if the hazrd ratio for becoming symptom-free is $<1$, then the symptom episodes are longer.

c Number of observations used in the analysis: any respiratory symptom [ $\mathrm{N}=504$ for symptom-free-intervals and $\mathrm{N}=389$ for symptom episodes (healthy cohort), $\mathrm{N}=175$ and 151 (hyperreactivity cohort), $\mathrm{N}=331$ and 307 (bronchitis cohort), $\mathrm{N}=339$ and 312 (asthma cohort)]; symptoms of the lower respiratory tract ( $\mathrm{N}=503$ and $314 / 175$ and $131 / 333$ and $293 / 338$ and 288 ); bronchitis symptoms ( $\mathrm{N}=505$ and $289 / 175$ and $118 / 334$ and $284 / 339$ and 255 ); asthma symptoms ( $\mathrm{N}=508$ and $132 / 180$ and $87 / 342$ and $183 / 343$ and 210$)$.

d Silent obstructives $(\mathrm{N}=18)$ having been excluded.

symptoms significantly decreased with exposure to environmental tobacco smoke in general and also exposure to environmental tobacco smoke including the workplace.

For none of the three variables by which we tried to quantify exposure to environmental tobacco smoke (ie, "daily duration of exposure", "number of smokers to whom the participant was exposed" and "number of years of exposure"), a consistent dose-dependent effect on the duration of intervals without and of episodes with respiratory symptoms could be established (results not shown).

\section{Discussion}

In our prospective analysis of daily symptom data from a large sample of never-smokers living in Switzerland, past self-reported exposure to environmental tobacco smoke was associated with adverse effects on both symptom-free intervals and the length of episodes of respiratory symptoms. The negative association with the duration of symptom-free intervals was strengthened and reached statistical significance for lower respiratory symptoms, bronchitis symptoms and asthma-like symptoms when the exposure was specified to include the workplace. The work-related association may partly reflect a dose-response relation as the higher hazard ratios for exposure at the workplace may be explained by a higher exposure in terms of hours and persons (results not shown). On the other hand, exposure to environmental tobacco smoke confined to places outside work showed a significant positive association with the average duration of episodes of any respiratory symptoms and symptoms of the lower respiratory tract. These results suggest that environmental tobacco smoke at the workplace may have an influence on mechanisms that affect the development of respiratory symptoms, whereas 
exposure to environmental tobacco smoke outside the workplace affects recovery from these symptoms. But the strong association between the duration of symptomfree intervals and exposure to environmental tobacco smoke at work may also indicate that most of the participants that developed respiratory symptoms because of passive smoking were exposed at work. No simple explanation can be found for this phenomenon, but we can imagine that many people exposed to environmental tobacco smoke at the workplace are not troubled by the exposure, while staying at home after getting sick. On the other hand, the illness of people exposed to environmental tobacco smoke only outside work (ie, mainly at home) may be protracted because they are exposed during their convalescent period at home.

The stratified analyses showed different effects of environmental tobacco smoke in the different cohorts. Some evidence of a negative influence of such exposure was even found in the originally healthy cohort, since episodes with bronchitis or asthma symptoms tended to last longer and intervals without bronchitis or lower- or upper-respiratory-tract symptoms tended to be shorter among the exposed participants classified as healthy in the baseline assessment. This negative influence was also shown by Jaakkola et al (7) in an 8-year longitudinal study on young adults that also showed that the symptoms tended to last longer. Exposure to environmental tobacco smoke was also associated with a shortening of symptom-free intervals and a prolongation of symptom episodes among the participants who reported symptoms related to asthma and bronchitis in the baseline assessment. On the other hand, the hyperreactive participants without respiratory symptoms at baseline surprisingly showed a paradoxical tendency to have fewer symptoms when exposed. This finding may be due to a selection effect. We therefore also considered the entire subgroup of nonobstructive hyperreactives (ie, including the hyperreactive participants from the symptomatic cohort). Indeed, the negative relation between exposure to environmental tobacco smoke and symptoms disappeared in this larger subgroup (results are not shown). One might thus hypothesize that nonsymptomatic hyperreactive persons exposed to environmental tobacco smoke are a selected subgroup with an increased tolerance level.

Our study provides additional evidence linking exposure to environmental tobacco smoke with a worsening asthma status. In the healthy and asthmatic cohorts, episodes of asthma symptoms were prolonged among the exposed participants. This finding is consistent with a recent update of Coultas (19), who reviewed several studies indicating that exposure to environmental tobacco smoke had a negative influence on the morbidity of adults' asthma. Results from the cross-sectional part of SAPALDIA (11) showed that exposure to environmental tobacco smoke is associated with a higher risk of physician-diagnosed asthma (odds ratio 1.39, 95\% CI 1.041.86). In a large Adventists' cohort, Greer et al (20) observed that, during 10 years of follow-up, exposure to environmental tobacco smoke at the workplace was significantly associated with an elevated risk (relative risk $1.5,95 \%$ CI 1.2-1.8) of developing asthma. In a population of 200 adult asthmatic patients, Jindal et al (5) observed that different indices of asthma morbidity reflecting acute episodes were significantly worsened when the patients were exposed to environmental tobacco smoke. In a 3-month diary study, Ostro et al (21) also found that a population of 164 asthmatic adults showed an increased frequency of different symptoms of asthma and higher morbidity indices (eg, restricted activity days and awakening by asthma) when exposed to environmental tobacco smoke.

This study adds to previous research by demonstrating that exposure to environmental tobacco smoke has a significant effect on both intervals without and episodes with bronchitis symptoms among never-smokers. According to our results, this effect was the most pronounced in the bronchitis cohort (particularly for the participants exposed to environmental tobacco smoke outside the workplace only). In his review of the effects of exposure to environmental tobacco smoke on chronic obstructive pulmonary disease (COPD), Coultas (19) mentioned that little is known about the effects of environmental tobacco smoke on respiratory symptoms among patients with COPD. Our results would be consistent with such an adverse effect, even if a direct comparison is difficult, as our bronchitis cohort was made up of nonsmoking people under 60 years of age with regular cough or phlegm, probably including only a few participants with clinically manifest COPD. This additional adverse effect of environmental tobacco smoke on participants with a history of symptoms may be highly relevant to the pathophysiological development of lung disease, as frequent lower-respiratory-tract illnesses among COPD patients have been associated with an increased rate of decline of FVC (forced vital capacity) and $\mathrm{FEV}_{1}$ (22). Moreover, the participants defined as nonsymptomatic and nonhyperreactive at the cross-sectional examination showed a tendency to report symptoms of cough and phlegm more frequently when exposed to environmental tobacco smoke, a finding in agreement with the higher prevalence of chronic symptoms among the participants exposed to environmental tobacco smoke in the cross-sectional study (11). This finding also tends to support the results of Kalandidi et al (23) and Robbins et al (3), which suggest an increased risk of developing COPD in relation to life-long exposure to environmental tobacco smoke.

Questionnaires are suitable instruments for evaluating exposure to environmental tobacco smoke in studies 
of health outcomes with a long-lasting latency period or long-lasting effects (24). The fact that exposure to environmental tobacco smoke was assessed prior to and not during the diary study is likely to have reduced recall bias from the participants who experienced symptoms and tried to find a cause for their pathologies (25). Furthermore, SAPALDIA was announced as a study of air pollution and lung diseases, and the questions on exposure to environmental tobacco smoke constituted only a small part of the questionnaire, thus reducing the likelihood of reporting bias. Although we used diary data to derive the individual characteristics of the symptom dynamics, we actually performed a cohort analysis in which health parameters assessed during follow-up were related to exposure at baseline. By its very nature, such an analysis cannot capture short-term effects of exposure, but it can help to predict how participants exposed at baseline will differ from unexposed participants at a later point in time. To address the important question of the reversibility of these effects, a follow-up study assessing exposure to environmental tobacco smoke at different times would be necessary.

In conclusion, this study supports evidence of adverse effects of exposure to environmental tobacco smoke on respiratory symptoms among adult neversmokers. The method of transition probabilities was used to estimate each participant's average duration of symptom-free intervals and symptom episodes in order to assess medium- to long-term effects of environmental tobacco smoke on the duration of symptom episodes and symptom-free intervals. This procedure allowed us to show place-dependent associations between exposure to environmental tobacco smoke and the duration of respiratory symptom episodes and intervals without such symptoms.

\section{Acknowledgments}

This study was supported by grants from the National Research Program 26A (grant no 4026-28099) of the Swiss National Science Foundation and from the Swiss Federal Office of Education and Science. SAPALDIA Basle is part of the European Respiratory Health Survey.

The first two authors have equally contributed to the present study.

The authors wish to thank the SAPALDIA team fieldworkers at Aarau, Basle, Davos, Geneva, Lugano, Montana, Payerne, and Wald. They are grateful to the collaborators of the central team at Basle (Institute of Social and Preventive Medicine), Lausanne (direction of the project), and Zurich (Allergology Unit, Department of Dermatology). They would like to thank Dr Sara
Downs for help with English grammar. The authors thank the authorities of the participating cantons of Aarau, Basle, Geneva, Vaud, Valais, Zurich, Ticino, and Grisons for their logistic and financial support.

\section{References}

1. Chan-Yeung M, Dimich-Ward H. Respiratory health effects of exposure to environmental tobacco smoke. Respirology 2003; June:131-9.

2. Samet JM, Lange P. Longitudinal studies of active and passive smoking. Am J Respir Crit Care Med 1996;154:S257-5.

3. Robbins AS, Abbey DE, Lebowitz MD. Passive smoking and chronic respiratory disease symptoms in non-smoking adults. Intern J Epidemiol 1993;22:809-17.

4. Jaakkola MS, Jaakkola JJK, Becklake MR, Ernst P. Passive smoking and evolution of lung function in young adults: an 8year longitudinal study. J Clin Epidemiol 1995;48:317-27.

5. Jindal SK, Gupta D, Singh A. Indices of morbidity and control of asthma in adult patients exposed to environmental tobacco smoke. Chest 1994;106:746-9.

6. Jaakkola MS, Jaakkola JJK, Becklake MR, Ernst P. Effect of passive smoking on the development of respiratory symptoms in young adults: an 8-year longitudinal study. J Clin Epidemiol 1996;49:581-6.

7. Schwartz J, Timonen KL, Pekkanen J. Respiratory effects of environmental tobacco smoke in a panel study of asthmatic and symptomatic children. Am J Respir Crit Care Med 2000;161:802-6.

8. Davey Smith G, Phillips AN. Passive smoking and health: should we believe Philip Morris's « experts »?. Br Med J 1996;313:929-33.

9. US Environmental Protection Agency (US EPA). Respiratory health effects of passive smoking: lung cancer and other disorders. Washington (DC): US EPA; 1992.

10. White JR, Froeb HF, Kulik JA. Respiratory illness in nonsmokers chronically exposed to tobacco smoke in the work place. Chest 1991;100:9-43.

11. Leuenberger P, Schwartz J, Ackermann-Liebrich U, Blaser K, Bolognini G, Bongard JP, et al. Passive smoking exposure in adults and chronic respiratory symptoms (SAPALDIA study). Am J Respir Crit Care Med 1994;150:1221-8.

12. Eisner MD, Smith AK, Blanc PD. Bartenders' respiratory health after establishment of smoke-free bars and taverns. JAMA 1998;280:1909-14.

13. Zemp E, Elsasser S, Schindler C, Kunzli N, Perruchoud AP, Domenighetti $\mathrm{G}$, et al. Long-term ambiant air pollution and respiratory symptoms in adults (SAPALDIA Study). Am J Respir Crit Care Med 1999;159:1257-66.

14. Martin BW, Ackermann-Liebrich U, Leuenberger P, Kunzli N, Stutz EZ, Keller R et al. SAPALDIA: methods and participation in the cross-sectional part of the Swiss Study on Air Pollution and Lung Diseases in Adults. Soz Präventivmed 1997;42:67-84.

15. Leuenberger P, Kunzli N, Ackermann-Liebrich U, Schindler C, Bolognini G, Bongard JP, et al. Etude suisse sur la pollution de l'air et les maladies respiratoires chez l'adulte (SAPALDIA). Schweiz Med Wochenschr 1998 ;128:150-61.

16. Ackermann-Liebrich U, Leuenberger P, Schwartz J, Schindler C, Monn C, Bolognini G, et al. Lung function and long 
term exposure to air pollutants in Switzerland. Am J Respir Crit Care Med 1997;155:122-9.

17. Kaiser R, Schindler C, Kunzli N, Ackermann-Liebrich U, Heeb D, Medici TC, et al. Use of transition probabilities to estimate the effect of smoking on the duration of episodes of respiratory symptoms in diary data (SAPALDIA). Am J Epidemiol 1998;148:600-8.

18. Wuthrich B, Schindler C, Medici TC, Zellweger JP, Leuenberger P. IgE levels, atopy markers and hay fever in relation to age, sex and smoking status in a normal adult swiss population. Int Arch Allergy Immunol 1996;111:396-402.

19. Coultas DB. Passive smoking and risk of adult asthma and COPD: an update. Thorax $1998 ; 53: 381-7$.

20. Greer JR, Abbey DE, Burchette RJ. Asthma-related to occupational and ambient air pollutants in non smokers. J Occup Med 1993;35:909-15.

21. Ostro BD, Lipsett MJ, Mann JK, Wiener MB, Selner J. Indoor air pollution and asthma: results form a panel study. Am J Respir Crit Care Med 1994;149:1400-6.

22. Kanner RE, Renzetti AD Jr, Klauber MR, Smith CB, Golden CA. Variables associated with changes in spirometry in patients with obstructive lung diseases. Am J Med 1979;67:4450 .

23. Kalandidi A, Trichopoulos D, Hatzaki A, Tzannes S, Saracci R. The effect of unvoluntary smoking on the occurrence of chronic obstructive pulmonary disease. Soz Praeventivmed 1990;35:12-16.

24. Jaakkola MS, Jaakkola JJ. Assessment of exposure to environmental tobacco smoke. Eur Respir J 1997;10(10):2384-97.

25. He J, Hughes J, Whelton P. Passive smoking and coronary heart disease [correspondence]. N Engl J Med 1999;341:697700 .

Received for publication: 23 August 2004 